\title{
Cervical Myelopathy due to Congenital Atlanto-axial Dislocation
}

\author{
PVS Rana, MD, DM \\ Department of Medicine \\ Manipal Teaching Hospital \\ Manipal College of Medical Sciences \\ Pokhara, Nepal
}

\author{
Mohit P. Shetti, MD \\ Department of Medicine \\ Manipal Teaching Hospital \\ Manipal College of Medical Sciences \\ Pokhara, Nepal
}

\section{Lekhjung Thapa, MBBS \\ Department of Medicine \\ Manipal Teaching Hospital \\ Manipal College of Medical Sciences \\ Pokhara, Nepal}

\author{
Address for correspondence: \\ PVS Rana, MD, DM \\ Professor of Medicine and Neurology \\ Department of Medicine \\ Manipal Teaching Hospital \\ College of Medical Sciences \\ Pokhara, Nepal \\ Email:rananirmal@fewanet.com.np
}

Five cases of atlanto-axial dislocation (AAD) are reported with emphasis on their clinical presentation and literature is reviewed. The first patient had gross AAD and presented as progressive myelopathy. The second patient had AAD with occipitalization of atlas, Chiari malformation and syringomyelia where headache was the only presenting symptom. The third patient with AAD, had occipitalization of atlas and fusion of cervical second and third (C2C3) vertebrae. She presented with peculiar sensation over forehead. Detection of pathologically brisk tendon reflexes in the lower limbs and extensor plantar response led to further investigation and diagnosis of the condition. The fourth patient had AAD and advanced spondylotic changes. His symptoms manifested after injury and then progressed gradually leading to quadriplegia. The fifth case presented with nuchal and occipital neuralgia, paresthesia in hands and brisk reflexes. X-ray cervical spine showed unfused, separate but fully developed odontoid process and AAD. All these patients represented congenitalAAD.

Key Words: Atlanto-axial joint (AAJ),basilar invagination, cervical myelopathy, congenital atlanto-axial dislocation(CAAD), craniovertebral junction $(\mathrm{CVJ})$ anomalies, syringomyelia.

Received, Novemebr 13, 2004

Accepted, November 15, 2004

A tlanto-axial joint (AAJ) is the most complex joint of the body and includes four joints. As this joint is kept stable by only joint capsule and ligaments, it is more prone to dislocation. Acquired AAD commonly develops following acute cervical trauma or due to slow erosion around the joints in, for example, tubercular arthritis,rheumatoid arthritis, ankylosing spondylitis. ${ }^{4,5,17}$ In addition isolated cases of AAD are also reported in association with Down's syndrome and Mucopolysacharroidosis (e.g. Morquio's syndrome). The craniovertebral junction ( $\mathrm{CVJ})$ anomalies constitute an important group of treatable neurological disorders. Congenital atlanto-axial dislocation (CAAD) is the commonest $\mathrm{CVJ}$ anomalies encountered in clinical practice. 2,19,22,23,24,29 In clinico-radiological practice CAAD accounted for $51.5-68 \%$ of all CVJ anomalies..$^{3,9,23}$ Bell $(1930)^{1}$ is credited with the first description of the case. In 1967 Wadia $^{30}$ classified them into three groups, (a) CAAD associated with segmental anomalies like occipitalization of atlas and C2-C3 vertebral fusion, (b) CAAD associated with maldeveloped odontoid process, ${ }^{8}$ and (c) CAAD without any other anomalies. One of the interesting features of CAAD is its varied clinical presentation ${ }^{18}$ and an unpredictable course. During last one year five cases of CAAD were seen at
Manipal Teaching Hospital, Pokhara, Nepal. Two of these had multiple CVJ anomalies. Their interesting clinical presentation forms the basis of this communication.

\section{Case Reports}

Case 1: This 55-year- old male presented with one and a half year history of gradually progressive weakness and numbness affecting right upper and lower limbs and difficulty in walking. He denied history of pain in the neck, or radicular symptoms, head injury, fever or of vaccination preceding the illness. Clinical examination revealed a relatively short neck, with quadriparesis of 4/5 strengh with upper limbs being weaker than the lower. There was a marked hyperreflexia with anke clonus. Sensory loss (pain and touch) was noted up to $\mathrm{C} 2$ level which was noted more on the right side. Romberg's sign was positive. X-Ray of the cervical spine (Figure 1A \&B) revealed AAD with the distance between the anterior arch of atlas and odontoid process being14 $\mathrm{mm}$ (normal $3 \mathrm{~mm}$ ) and the distance between posterior arch of atlas, $11 \mathrm{~mm}$ (normal $19 \mathrm{~mm}$ or more). The dislocation increased with flexion of neck.

Case 2: This 32-year-old lady presented with complaints 

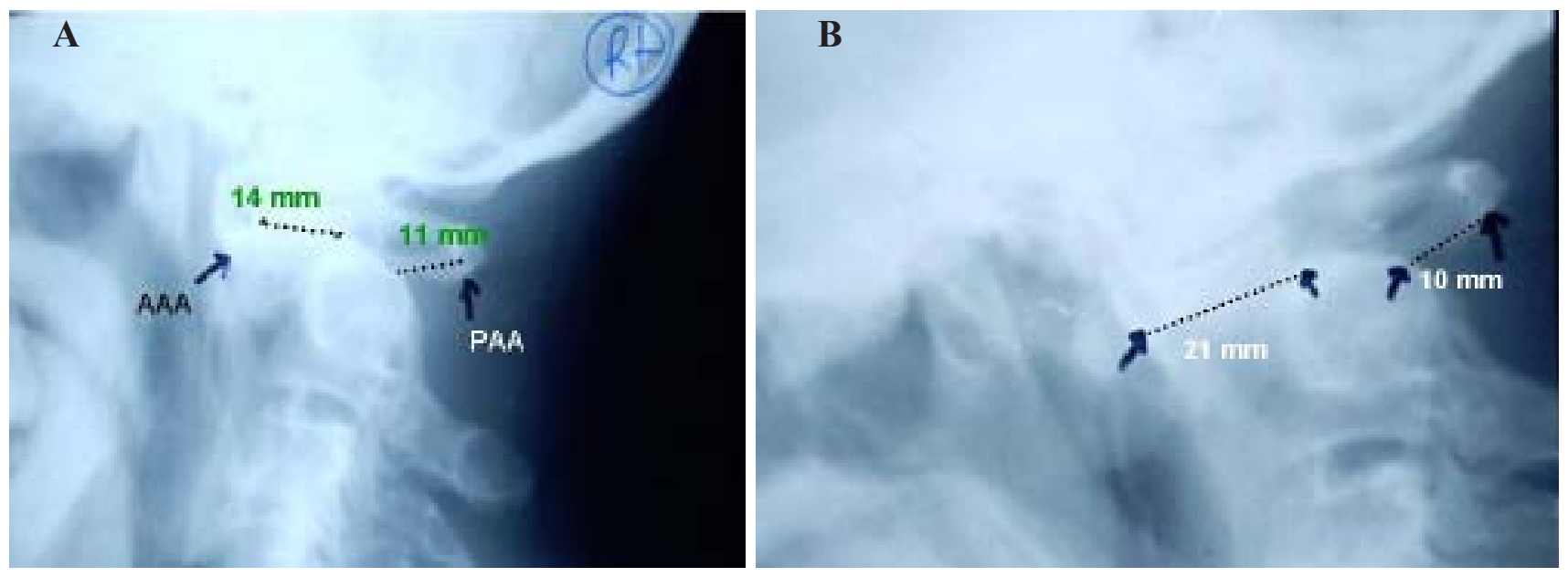

Figure 1. Plain X ray of cervical spine including craniovertebral junction. A)Gross atlanto-axial dislocation with hypoplastic Odontoid Process. B) X-ray of the same patient on flexion. Changing distance on flexion suggests mobile dislocation.

of predominantly left sided paroxysmal headache of one month duration. There was no diplopia, vomiting, seizures or loss of consciousness. She denied a history of trauma, fever or ear infection. Family history was negative. Clinical examination revealed an averagely built lady with a normal general physical examination. Neurological examination did not reveal any motor or sensory deficits except for brisk deep tendon reflexes in the lower limbs with extensor plantar response on both sides. X-Ray of the cervical spine (Figure 2A\&B) revealed occipitalization of atlas and AAD. The spinal canal diameter (i.e. distance between odontoid process and the posterior margin of foramen magnum) was measured to be $18 \mathrm{~mm}$ on extension and $15 \mathrm{~mm}$ on flexion respectively. A magnetic resonance imaging (MRI)of the cervical spine confirmed the diagnosis. In addition it showed the Chiari malformation and syringomyelia (Figure 2C). She was referred to neurosurgical center where posterior decompression with posterior orhtodesis was performed . On follow-up after one month she had complete resolution of her headache.

Case 3: This 38-year- old lady presented with peculiar sensation over the forehead and deep seated pain in her left upper limb of three years duration. Over the period her symptoms remained static. Her neurological examination revealed diminished touch sensation over forehead on both sides. No motor deficit was detected. Deep tendon reflexes were brisk and plantar response was extensor on both sides. $\mathrm{X}$-ray of the cervical spine revealed fusion of C2 and C3 vertebrae, occipitalization of atlas and AAD with spinal canal at CVJ being $18 \mathrm{~mm}$ during extension and $12 \mathrm{~mm}$ during flexion respectively (Figure 3A \&B). Subsequent MRI confirmed the diagnosis No soft tissue abnormality was detected. She refused surgical treatment.

Case 4: This 80-year-old male, sustained injury two years back when he fell down and developed nuchal pain and weakness of upper and lower limbs. This weakness progressed gradually. He was bed ridden for 5-6 months and had retention of urine seven days prior to his admission. He was poorly nourished and had bed sores on the sacral region. Neurological examination revealed torticollis and spastic quadriparesis (power 3/5), brisk deep tendon reflexes (except triceps reflex which was normal), bilateral extensor plantar response and a sensory loss up to $\mathrm{C} 2$ level . X-ray of the cervical spine revealed gross AAD with subluxation of C2 and C3 vertebrae \& advanced spondylotic changes. The spinal canal at CVJ was $19 \mathrm{~mm}$ in extension and $3 \mathrm{~mm}$ during flexion (Figure $4 \mathbf{A} \& \mathbf{B}$ ).

Case 5: This 60-year-od female, presented with nuchal pain involving upper part of the neck and occipital region being aggravated by neck movement. It was accompanied by diffuse paresthesia in both upper limbs. She denied history of trauma. Clinical examination revealed hyperreflexia and mute plantar response. Sensory examination was normal. Romberg's sign was negative. Tandem walking was normal. Her x-ray of the cervical spine (Figure 5) showed welldeveloped odontoid process separate from dens (os Odontium).

\section{Discussion}

CAAD constitutes an important group of $\mathrm{CVJ}$ anomalies frequently requiring emergent decompression and stabilization of joint to prevent morbidity and mortality resulting from compression of neurovascular structures at CVJ. Although present at birth it often manifests at a later date (usually by the third decade) often following trauma. The injury at times may be minor and hence forgotten by the patient. When present, the severity of neurological symptoms and its progression has no relation to the degree of injury sustained by the patient. It is suggested that chronic recurrent trauma during neck movement and during daily activities of living is an important factor for making the illness symptomatic and its sudden aggravation. Because of its varied neurological manifestations and an unpredictable course, CAAD is often misdiagnosed. Its usual manifestation include nuchal pain and stiffness, progressive cervical myelopathy, foramen magnum syndrome or as sudden death due to compression of vital 

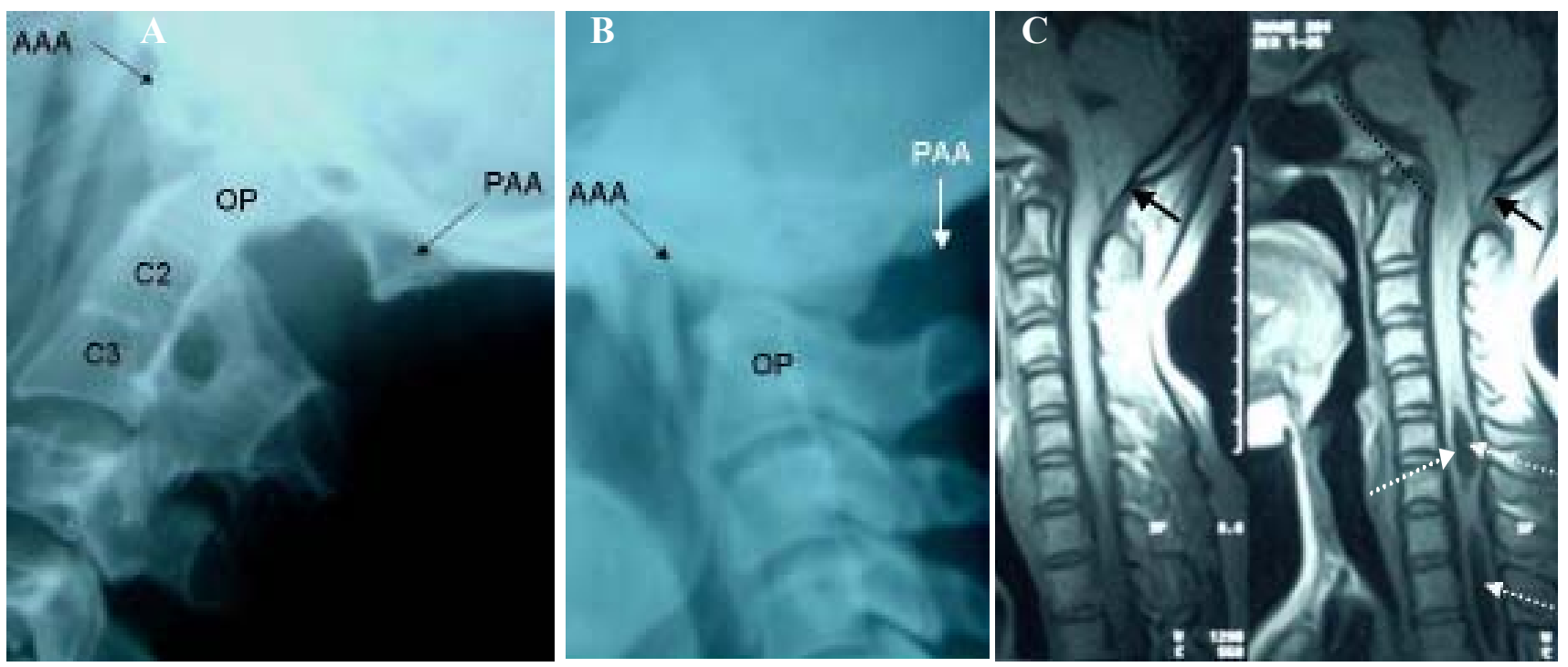

Figure 2. X-ray of cervical spine in Extention (A) and Flexion (B) showing assimilation of the arch of atlas OP:Odontoid Process; $A A A=$ anterior arch of atlas, $O P=$ Odontoid process; $P A A=$ posterior arch of atlas. $C)$ MRI of the cervical spine of the same patient showing Chiari malformation with associated cervical syrinx (white arrow).

structures at cervicomedullary junction. It can present as myelopathy in any combination. (i.e. quadriplegia, paraplegia, weakness of both upper limbs only, crossed paralysis (involvement of upper limb on one side and lower limb on other side) or a hemiplegic presentation).

CVJ has important relationship with vertebral arteries and it's branches (i.e. meningeal and anterior spinal arteries), internal and external carotid arteries. The most important is vertebral artery which is tightly held in the transvese foramina of $\mathrm{C} 6-\mathrm{C} 3$ and then runs through a knee shaped bony tunnel in the lateral masses of axis and finally curving around the lateral aspect of atlantoaxial articulation. ${ }^{12}$ The inferior cerebellar artery may arise at, above or below the level of foramen magnum. Clinical problems (i.e. vertigo, tinnitus, nausea and visual disturbances) may occur as a result of extreme rotation at $\mathrm{C} 1-\mathrm{C} 2$ articulation. With axial rotation of head in one direction, on the side away from the direction in which head turns, $\mathrm{C} 1$ vertebra moves forward in relation to the lateral portion of the axis. The contralateral artery is first affected at $30^{\circ}$ rotation and it becomes markedly kinked at $45^{0} .^{21}$ The unstable AAJ may compress these arteries and patients may present with cerebrovascular accidents involving posterior circulation. Presentation as anterior circulation stroke has also been reported. ${ }^{31}$

The reducible AAD results in repeated transient compression at $\mathrm{CVJ}$ for variable period resulting in an illness resembling multiple sclerosis or TIAs. Other rare manifestations include presentation as (a) sleep attacks resembling narcolepsy due to interruption of respiratory medullary drive by compression at $\mathrm{CVJ},{ }^{10}$ (b) obstructive hydrocephalus due to presence of soft tissue abnormality (i.e. Chiari malformation) and adhesions at CVJ causing obstruction of $4^{\text {th }}$ ventricular foramina, (c) aphonia, ${ }^{23}$ and (d) cervical myelopathy with wasting of hand muscles, attributed to anoxia of cervical spinal cord grey matter due to venous stasis, ${ }^{27}$ resembling central cord syndrome and motor neuron disease. Our Case 3 had another rare presentation as peculiar sensory sensations on the forehead related to the affection of lower end of spinal tract of trigeminal nerves which extends up to $\mathrm{C} 2$ vertebra and represents the $1^{\text {st }}$ division (i.e. ophthalmic) of trigeminal nerve.

Many notable workers have immensely contributed towards the radiological diagnosis of these disorders. Preliminary screening requires plain X-ray of cervical spine on flexion and extension. AAD is diagnosed when distance between the anterior arch of atlas and the odontoid process is more than three $\mathrm{mm}$ in adult and more than four $\mathrm{mm}$ in children or when the width of spinal canal (measured between posterior surface of odontoid process and the posterior arch of atlas or post rim of foramen magnum) is less than $19 \mathrm{~mm} .{ }^{15}$ When odontoid process is separate or maldeveloped, the above distance can be measured from anterior and posterior edge of body of axis. The CAAD may be irreducible when dislocation distance remains unchanged or reducible when dislocation distance is variable on flexion and extension of neck.

Transverse ligament is $10 \mathrm{~mm}$ in thickness. It is attached to the tubercle on the medial side of the lateral masses of atlas. It can withstand a large force. Diagnosis of traumatic $\mathrm{AAD}$ is made when patient gives history of injury followed by pain in neck and the distance between arch of atlas and odontoid process is more than three $\mathrm{mm}$ or when avulsed bony fragment is seen on CT scan. Diagnosis of mild substance rupture of transverse ligament can also be made on MRI. The rotatory atlantoaxial subluxation can also occur spontaneously or after trauma but the exact mechanism is not known. In these cases, the open mouth anteroposterior (AP) view will show the lateral mass rotated anteriorly and towards the midline. The joint spaces of the lateral mass rotated posteriorly appear to be overlapping the one below. The $\mathrm{C} 2$ spinous process is rotated off the midline on AP view. Failure of $\mathrm{C} 1$ to reoppose again on left or right rotation indicates a fixed deformity. Rotatory atlanto-axial subluxation is Type 1 if anterior arch and dens distance is three $\mathrm{mm}$ 


\section{Congenital Atlanto-axial Dislocation}
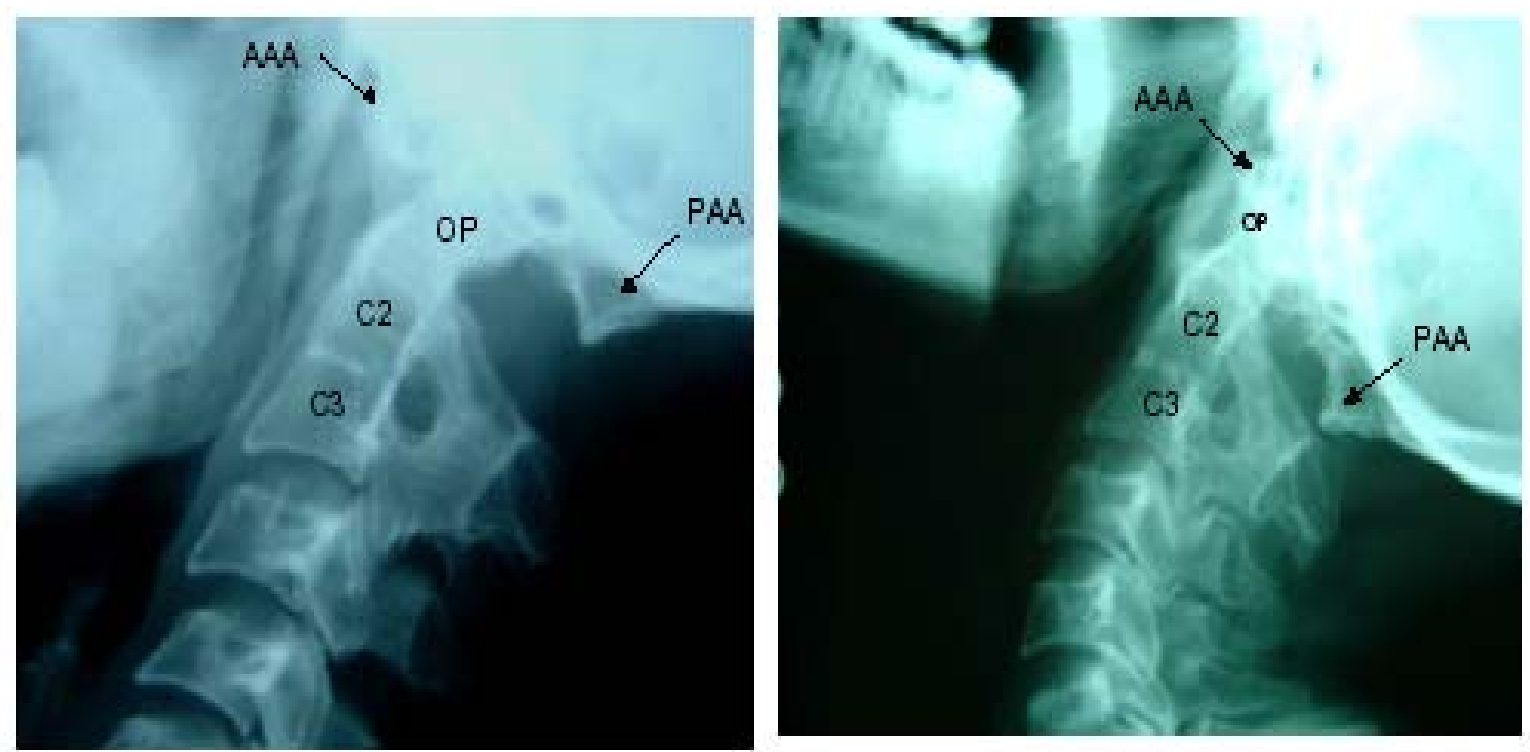

Figure 3. X-ray cervical spine Flexion (A) and Extension (B) view: Assimilation of the arch of atlas, atlanto-axial dislocation \& fusion of $C 2$ and 3 .

and the transverse ligament is intact. This distance is 3-5 mms in Type 2 and more than five mm inType 3 rotatory atlantoaxial subluxations respectively. In Type 4, there is complete posterior displacement of atlas. ${ }^{26}$

Computed tomography (CT) scan and MRI are now the investigation of choice. ${ }^{14,20}$ While Spiral CT scan with reconstruction in sagittal and coronal plane offer superior display of the bony anomaly and is excellent for post operative follow up, MRI is sensitive and accurate in demonstration of soft tissue abnormalities, delineate CSF pathways and vascular system can often be evaluated without the need of contrast injection. The recommended MRI sequences are T1 and T2 W spin echo sequences in sagittal plane (to delineate soft tissue and their abnormalities), GRE sequence in sagittal and coronal plane in flexion and extension (for osseous details \& demonstration of reducibility) and 3-D time of flight GRE sequences for MRI angiography. The sequences can be done in flexion and extension in sagittal plane as well. The cortical bone is devoid of any signal on all sequences. The medullary cavity shows signals depending upon the type of marrow it contains. Fatty marrow is seen as hyperintense signal in T1WI and slightly hyperintense signal on T2WI while red marrow is hypointense on T1WI and slightly hyperintense on T2WI respectively. Ligaments are hypointense on all sequences. The cord has intermediate signal intensity on both T1 and T2WI and can be easily differentiated. Spiral CT scan with reconstruction in sagittal and coronal plane offer superior display of the bony anomaly and is excellent for postoperative follow up.

The age group of the cases under discussion varied from 32 years to 80 years. Radiological evaluation revealed marked CAAD with distance varying in flexion and extension in all cases. In addition Case $2 \& 3$ had assimilation of atlas. While additional soft tissue abnormalities i.e.Chiari malformation and syringomyelia were detected in Case 2. Case 3 had fusion of C 2 and C 3 vertebra. Case 5 had separate odontoid process. The patients under discussion had varied clinical presentation i.e. progressive cervical myelopthy with features of extramedullary compression (Case $1 \& 4$ ), headache only (Case-2) and a peculiar burning sensation over forehead and anterior scalp (Case 3). It is only on detection of pyramidal signs in Case- $2 \& 3$ and hyper-reflexia, a cervical pathology was suspected. The presenting feature of paraesthesia over forehead in Case 3 was an interesting feature which may be seen in high cervical compression due to irritation of spinal tract of trigeminal nerve which extend upto $\mathrm{C} 2$ vertebral level and has ophthalmic division representation at its lower end. In Case 4 , the symptoms of cervical myelopathy were noted after a fall and then it progressed gradually over a period leading to a bed-ridden stage. As no fracture was detected, the AAD was considered of congenital origin and aggravated by injury. A characteristic feature of these cases was the development of weakness, which is out of proportion to the severity of injury.

Occipitalization of atlas can be complete, partial or symmetrical and may be seen as an isolated abnormality or as part of more complex anomalies with CAAD, basilar invagination, C 2 C 3 fusion, syringomyelia and Chiari malformation. Two of our patients (Case $2 \& 3$ ) had occipitalization or fusion or assimilation of atlas in addition to CAAD. While the reported incidence of occipitaliztion of atlas in general population is $0.08-3 \%,{ }^{28}$ a higher incidence of $38 \%$ to $51.5 \%$ was observed in patients with CAAD. ${ }^{3,24}$ Occipitalization and $\mathrm{C} 2 \mathrm{C} 3$ fusion is the commonest association with CAAD and was seen in Case 3. The transverse ligament in this anomaly is either abnormal or absent and is the cause of unstable AAJ and subsequent AAD.

The Case-2, a 32 years lady, had CAAD with occipitalization of vertebra and Chiari malformation and syringomyelia and manifested with nuchal pain and stiffness only. Review of 252 cases of Chiari malformation ${ }^{16}$ revealed its association with syringomyelia in $72.3 \%$ cases. The majority of patients were in the third decade. There was no 

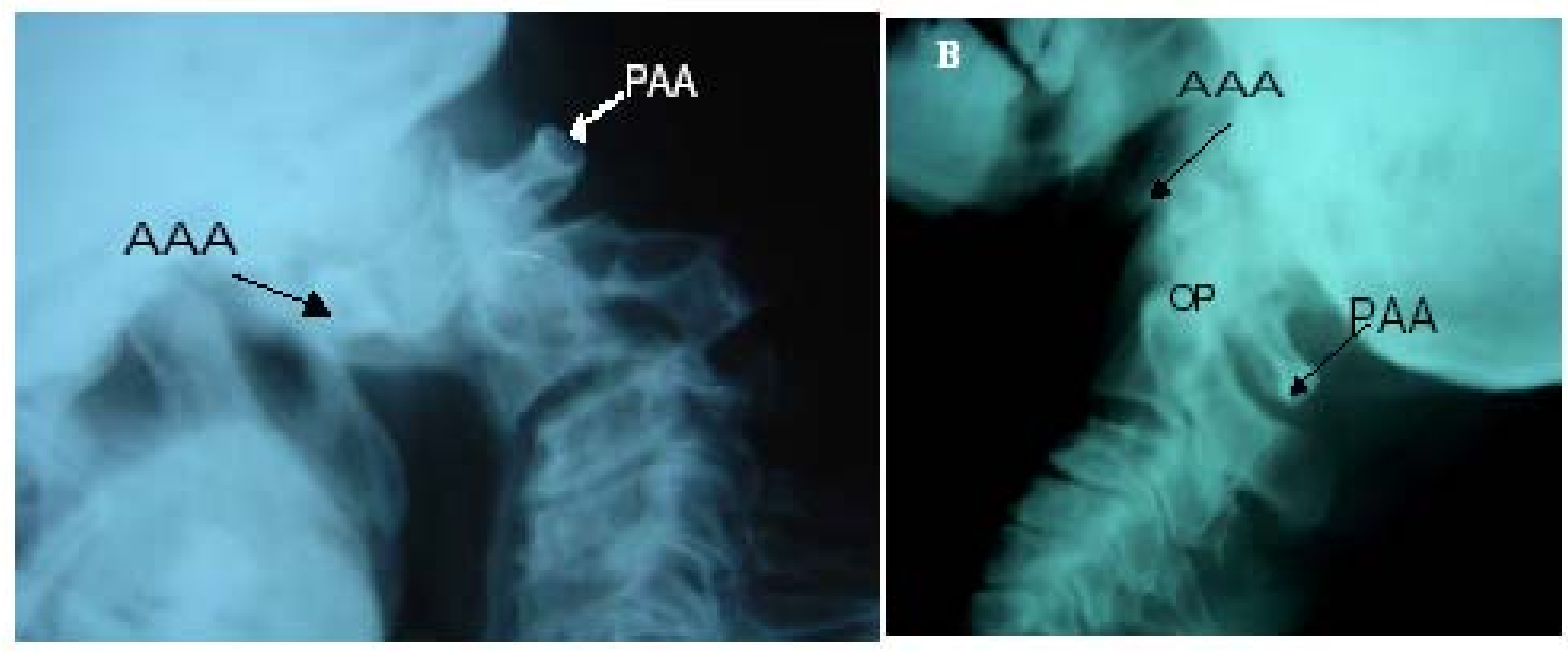

Figure 4. X-ray cervical spine on flexion (A) and extension (B) showing atlanto-axial dislocation and C2 C3 subluxation and marked narrowing of the spinal canal. Note that on extension there is reduction of dislocation and subluxation.

sex preponderance. The Chiari syrinx group presented with foramen magnum compression syndrome in $40.3 \%$, central cord dysfunction in $49.1 \%$ and cerebellar syndrome in $4.4 \%$ cases respectively. Weakness in one or both upper limbs and sensory loss was noted in $65.57 \%$ and $78 \%$ cases respectively. The most common finding was the hyperreflexia in lower limbs and atrophy of upper limbs .The classical dissociate sensory loss was noted in $30.7 \%$ cases only. In contrast, the case under discussion manifested with symptoms of nuchal pain and stiffness, hyperreflexia and an extensor plantar response on both sides. Typical dissociate sensory loss and wasting was not detected despite the presence of a large syrinx.

The CAAD constitutes an emergency requiring prompt decompression, immobilization and stabilization to prevent damage to the vital structures at CVJ. Various approaches are described i.e. posterior decompression and occipitocervical fusion, anterior decompression and anterolateral approach followed by stabilization either by posterior approach or through anterior route itself and additional fixation of lateral masses of atlas and axis. Orthodesis by posterior approach is commonly employed to achieve a stable fusion especially when atlantococcipital instability is present due to occipitalization of atlas and when posterior decompression is needed. When posterior compression is not reducible and there is ventral compression, anterior transoral approach is employed and odontoid process is excised. ${ }^{5}$ In situations requiring wider exposure other approaches i.e. transpalatal for approaching anterior rim of clivus for higher basilar invagination and Trans glossal ${ }^{13}$ or mandible and tongue splitting approach for the exposure of upper cervical spine for spinal decompression can be used. ${ }^{11}$ Anterior approach is followed by stabilization either by posterior approach or through anterior route itself with additional fixation of lateral masses of atlas and axis. ${ }^{7}$ Abnormality of somatosensory evoked potential (SSEP) and binaural auditory evoked potential (BAER) are reported in patients with ventral compression. This improves after excision of adenoid process. Evoked potential studies may help in recognizing these patients when basilar invagination is present. ${ }^{25}$

Nair, et al., in $1977^{16}$ operated 183 cases of CVJ anomalies with Chiari malformation associated with syrinx with posterior decompression through suboccipital craniotomy. C2 laminectomy was done when tonsilar herniation extended beyond $\mathrm{C} 1$ arch. Additional procedures included duroplasty in 113 patients, Gardener's procedure in 44, excision of tonsils in six, ventriculoperitoneal or ventriculoatrial shunt in two, syringosubarachnoid shunt (SSS) in nine patients. Following operation improvement was noted in $26 \%$ cases of foramen magnum compression syndrome group and in $24 \%$ of central cord syndrome group respectively. Seven patients deteriorated after initial improvement requiring subsequent syringosubarachnoid shunt procedure.

The case under discussion (Case 2) underwent posterior decompression and fusion with improvement in her symptoms of nuchal pain but her neurological examination remained stable. The other four patients were lost to follow up.

\section{References}

1. Bell C: The Nervous System of Human Body. Longman, Rees, Orme, Brown an Green, London, 1930

2. Bhagwati SN: Congenital atlanto-axial dislocations. A study of 99 cases. Neurol India 38:317-324, 1990

3. Chopra JS, Sawhney IMS, Kak VK: Craniovertebral anomalies: a study of 82 cases. British J Neurosurg 2:455-464, 1988

4. Clark Cr, Goetz DD, Menezes AH: Arthrodesis of the cervical spine in rheumatoid arthritis. J Bone Jt Surg 71(Am):381-392, 1988

5. Crockard HA: Midline ventral approach to the craniocervical junction and upper cervical spine, in Sheek HH(Ed): The Cervical Spine. An Atlas of Surgical Procedures. JB Lippincott Company, Philadelphia, 1994, pp 93-112

6. Crockard HA, Calder I, Ransford AO: One stage transoral decompression and posterior fixation in rheumatoid atlantoaxial subluxation. J Bone Jt Surg 72 B:682-685, 


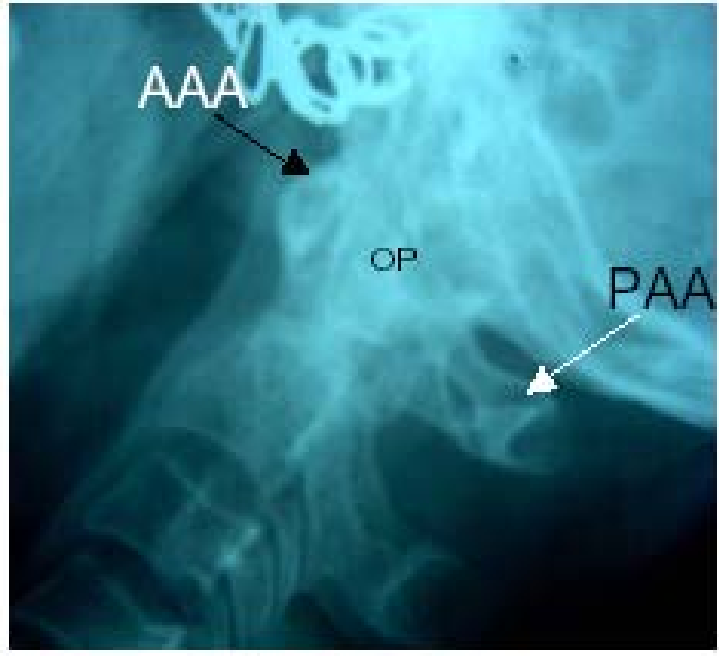

Figure 5. X-ray cervical spine lateral view showing odontoid process separate from the C2 body..

\section{0}

7. Goel A, Laheri V: Plate and screw fixation for atlantoaxial subluxation. Acta Neurochir (Wein) 129:47-53, 1994

8. Greenberg AD: Atlantoaxial dislocation. Brain 91:655684,1968

9. Gupta SK,Khosla VK, Sharma BS, et al: Craniovertebral Junction Anomalies-PGI Chandigarh experience, in Jain VK, Behari S (eds): Craniovertebral junction anomalies: The Indian experience. Sanjay Gandhi Post Graduate Institute of Medical Sciences, 1997, pp176-184

10. Hall CW, DanoffD: Sleep attacks-apparent relationship to atlantoaxial dislocation. Arch Neurol 32:57-599, 1975

11. Hall JE, Dennis F, Murray J: Exposure of upper cervical spine for spinal decompression by mandible and tongue splitting operation. J Bone Joint Surg Am 59:121, 1997

12. Jones RT: Vascular changes occurring in the cervical musculoskeletal system. Afr Med J 40:388-390, 1996

13. Khosla VK, Gupta SK: Transoral surgery: Principles and technique in craniovertebral junction anomalies: The Indian experience. Sanjay Gandhi Post graduate Institute of Medical Sciences, 1997, pp 42-43

14. Kumar S: CT and MRI of craniovertebral junction, in Jain VK, Behari S (eds): Craniovertebral junction anomalies: The Indian experience. Sanjay Gandhi Post Graduate Institute of Medical Sciences, 1997, pp 25-30

15. McRae DL: Bony abnormalities in the region of foramen magnum. Acta Radiol 40:335-340, 1953

16. Nair S, Menon G, Kurian NI, et al: Symptomatic Chiari malformation: Surgical outcome, in Jain VK, Behari S (eds): Craniovertebral anomalies: Indian experience.
Sanjay Gandhi post Graduate Institute of medical Sciences, Lucknow, 1997, pp 6-132

17. Ramani PS, Sharma A: A standard protocol for the management of craniovertebral junction anomalies in Indiaexperience at L.T.M. Medical College \& Hospital, Mumbai, in Jain VK, Behari S (eds): Craniovertebral anomalies: Indian experience. Sanjay Gandhi post Graduate Institute of medical Sciences, Lucknow, 1997, pp 97-105

18. Rana PVS, Sahai B, Biswas S, et al: Compressive myelopathy due to atlanto-axial dislocation. Medical Journal of Armed Forces of India 39:109-112, 1983

19. Rao BS, Taraknath VR, Sista VN: Congenital atlantoaxial dislocation. Annals Acad Med 22:847-851, 1993

20. Ross JS, Kaufman B: Cervicomedullary and craniovertebral junction, in Medic MT, Massaryk TJ, Ross JS (eds): Magnetic Resonance Imaging of Spine. USA Year Book Medical Publishers, 1989, pp149-166

21. Selecki BR: The effects of rotation of atlas on the axis: an experimental work. Med JAust 1:102-1015, 1969

22. Sherk HH, Snyder B: Posterior fusions of the upper cervical spine. Indications, technique and prognosis. Ortho Clin North Am 9:1091-1099, 1979

23. Shukla R, Nag D, Gupta NN, et al: Congenital atlantoaxial dislocation: A clinical and radiological study. J Assoc Physicians India 32:697-700, 1984

24. Singh G: Congenital atlanto-axial dislocation. Neurol India 24:69-76, 1976

25. Sood S, Mahopatra AK, Bhatia R: Somatosensory and brainstem auditory evoked potentials in congenital craniovertebral anomaly, effect of surgical management. J Neurol Neurosurg \& Psychiatry 55:609-612, 1992

26. Stauffer ES, Macmillan M: Fracture and dislocation of cervical spine, in Rockwood CA, Green RW, Bucholz RW, Heckman JD (eds): Rockwood and Green's Fractures in Adults. Lippincott- Raven publishers, New York, Philadelphia, Volume 2, Chapter 22, pp1483-1484

27. Taylor AR, Bymes DP: Foramen magnum and high cervical cord compression. Brain 97:473-480, 1974

28. Wackenheim A: Roentgen diagnosis of craniovertebral region. Berlin, Heidelberg, New York, Springler Verlag, 1974

29. Wadia NK: Chronic progressive myelopathy complicating atlantoaxial dislocation due to congenital anomaly. Neurol India 8:81, 1960

30. Wadia NK: Myelopathy complicating congenital atlantoaxial dislocation: a study of 28 cases. Brain 90:449-472, 1967

31. Wadia NH: Congenital atlantoaxial dislocation and its manifestations, in Spillane JD(ed): Tropical Neurology. Oxford University Press, London, 1973, pp 99-107 